\title{
Research on risk evaluation of BIM application in military engineering project management
}

\author{
ZHU Pu ${ }^{* 1, a}$, Liu Xiao dong ${ }^{2}$, GUO Rui ${ }^{3}$, Yang Chun $\operatorname{lin}^{4}$ \\ ${ }^{1}$ School of Equipment Management and UAV Engineering Air Force Engineering University Xi an, Shan xi province \\ ${ }^{2}$ School of Equipment Management and UAV Engineering Air Force Engineering University Xi an, Shan xi province \\ ${ }^{3}$ School of Equipment Management and UAV Engineering Air Force Engineering University Xi an, Shan xi province \\ ${ }^{4}$ School of Equipment Management and UAV Engineering Air Force Engineering University Xi an, Shan xi province
}

\begin{abstract}
With the deepening of the reform of national defense and the military, the defense strength of China has been greatly enhanced, and the number of military engineering projects has also increased year by year. The complexity and large-scale construction of engineering projects make it difficult for the traditional military's engineering project management to meet current needs. This puts forward higher requirements for the military's engineering project management ideas and methods. The refined and intelligent military engineering project management has become our military's Matters that need to be focused on. Building Information Modeling (BIM) is a hot technology and a new production management method in the current construction industry, which provides us with a more advanced and intelligent military engineering construction project management idea. This paper identifies the risks of applying BIM technology to military engineering projects by consulting a large amount of data, and uses SPSS software to conduct neural network analysis of the identified risks and proposes corresponding measures to promote the extensive use of BIM in military engineering project management.
\end{abstract}

\section{Introduction}

With the rapid development of national defense and the military, military engineering infrastructure projects, as the basis for guaranteeing combat effectiveness, put forward higher requirements on the progress, quality and management level of engineering construction. Due to the particularity of military engineering projects, there are still many problems in management ${ }^{[1-2]}$. BIM (Building Information Modeling), as a hot spot of current engineering projects and the key technology of future construction engineering informatization, although it started late, its application in china has developed significantly ${ }^{[4,3-6]}$. Various researches on BIM, from the beginning of the technical level of virtual reality, collaborative design and visualization as the focus, to the later full life cycle BIM management and teaching reform as the research direction, reflecting that BIM is not only a technology, but also A new management method ${ }^{[3,7-9]}$. In the future BIM development process, strengthen the understanding and research of BIM technology, so that BIM can play a role in the entire life cycle of military engineering construction projects.

\section{Problems in the management of military engineering projects and the advantages of applying BIM}

\subsection{Problems in the management of military engineering projects}

The first is that the project management of the construction unit is more arbitrary. In the military's engineering projects, whether it is plan design, project implementation, material procurement, and cost control, to a large extent, leaders make a final conclusion, lacking detailed and professional research and analysis; in addition, there is a lack of supervision and management decision-making in the decision-making process. Unscientific and unreasonable phenomena occur from time to time, causing confusion in the later stage of project construction, frequent plan changes, and difficulty in achieving project management goals.

Secondly, the management capacity of the engineering construction unit is insufficient. Engineering construction projects involve many specialties, a wide range of construction operations, and complex construction units and personnel. There are many issues that need to be coordinated and docked between participating units, and between the military and local governments. This requires managers to have a high comprehensive management 
quality. However, most of the construction unit personnel lack professional and systematic management knowledge learning, and management knowledge basically comes from work accumulation, which is far from meeting the increasingly complex project management requirements.

Finally, the military engineering project management model is single. At present, most military construction projects use the parallel contracting model, which causes the construction unit to conduct multiple bids and manage multiple contractors at the same time. Contract management pressure is relatively high, and the quality and efficiency are generally low. In addition, parallel contracting has caused the design, procurement, and construction units of project construction to intervene in the project construction only according to the order of project progress, increasing the project construction cycle, and each participating unit is likely to set up barriers to each other and create information islands, making project management inefficient.

\subsection{Advantages of applying BIM}

With reference to the characteristics of military engineering projects and the highlights of BIM technology, the introduction of BIM technology will bring more convenience to military engineering project management and improve the current traditional military engineering project management existing many problems ${ }^{[10]}$.

First of all, based on the military engineering project management under the BIM model, in the design, the relevant content of the use of BIM for life cycle management is taken into consideration. In the process of approval and contracting, each participating unit determines the responsibility and scope in the form of contract.

Secondly, in the process of project design, procurement, and construction, professionals use a large amount of engineering data from BIM and other related software to manage the design, procurement, and construction phases, avoiding the lack of professional quality of military personnel and incomplete information grasp. The poor communication and coordination between the military and the civilians caused deviations in project quality, schedule, and cost, which greatly improved the efficiency of project management.

Finally, under the BIM management mode, the coordination of the participating units is smoother, from the traditional consideration of one and the other to the timely and dynamic information exchange and sharing, which is convenient for managers to grasp the key points. In the process of project handover, all BIM information is handed over with the entity, which is conducive to management, operation, maintenance and evaluation in the later stage. This also makes BIM a management method that runs through the beginning and the end to ensure the smooth progress of the project.

\section{Risk identification of BIM application in military engineering project management}

According to the project management and engineering practice of china, in the process of project risk management, risk identification, risk analysis and evaluation, risk response, risk control and prevention are generally used for risk management. Combining BIM management technology and characteristics of military engineering projects, this article analyzes the risks of military engineering project management BIM application from four aspects: organization, economy and management, engineering environment, and technology. By consulting a large amount of data, summarizing relevant risk factors ${ }^{[4,11-14]}$, and conducting interviews with experts in related fields such as engineering management and BIM application, it is planned to focus on four aspects: organizational risk, economic and management risk, engineering environmental risk, and technical risk.

\subsection{Organizational risk}

In organizational risk, it is necessary to consider aspects such as organizational structure, work flow, division of tasks and management, personnel composition and capabilities.

Business process reorganization risk: it is difficult to integrate BIM applications with traditional military engineering models, and the connection between the new and old models is not high. The inadequacy of new technologies and new methods makes the driving force of military engineering project reform insufficient, and decision makers are not determined enough. Participating party cooperation risk: the focus of the use of the BIM model is implementability, but from the perspective of participants, more consideration is given to benefits and ease of implementation. When military engineering projects are located in complex construction environments such as mountains, islands, deserts, and Gobi, the BIM model cannot be effectively used on site, the coordination of various disciplines is difficult, and the willingness of participating parties to cooperate is not strong. BIM implementer risk: the local and military generally lack software understanding, BIM talents who understand design, construction and management have greatly restricted the promotion and use of BIM in the military. Operator initiative risk: military engineering construction projects are tight in time, heavy tasks, and strict, and BIM technicians are accustomed to their familiarity method to saves time and effort, and deliberately avoids new technologies.

\subsection{Economics and management risks}

In economic and management risks, it is necessary to consider the macro and micro economic conditions, capital status, contract risks, and various security control plans.

Unclear BIM requirements risk: currently, BIM technology in China's local engineering and construction 
industry is mostly used in the initial model construction and some professional aspects. Clearly, the selection of technology is not appropriate, and it is impossible to make clear requirements. Resource risk: BIM technology requires more resources when participating in military engineering construction projects, purchase relevant platform software, cultivate BIM professionals, BIM modeling review, expensive training expenditure, high time cost, and there is currently no special funds for BIM, and compared with traditional CAD modeling, the initial investment is large. Once the management is slightly deviated, there will be extra human and financial expenditures such as unplanned design revisions and legal disputes, resulting in increased costs and resource waste. Security management risk: in the process of construction, the application of BIM needs to be completed by multiple parties. In the process of data search, update, interaction and project management, each participant lacks awareness of confidentiality, loses and leaks secrets, and pays disastrous cost. Feasibility of plan implementation risk: in the process of construction project implementation, the actual construction situation and the BIM plan are quite different, and the cooperation of all participants is not coordinated, and the final plan is difficult to implement smoothly. Contract risk: The type of traditional bilateral agreement in the process of BIM application cannot meet the actual contract requirements. There are many difficulties in the cooperation mode, rights and obligations, benefit distribution, knowledge and data copyright in BIM among the participating parties, which brings challenges to the existing contract management.

\subsection{Engineering environmental risks}

In engineering environmental risks, the natural environment, industry environment, internal environment, etc. need to be considered.

Lack of standard risk: The current lack of BIM-related legal standards in the military, including data exchange standards, BIM application capability assessment criteria, BIM project implementation specifications, process standards, model establishment criteria, and delivery and acceptance criteria, there is a lack of corresponding specifications in all phases of project construction. Insufficient acceptance risk: the application of new technologies and increasingly complex military engineering construction projects make the acceptance of engineering more difficult, the acceptance capability becomes more and more insufficient, and the quality of the project cannot be tested. Recognition risk: the military engineering construction has a long history, the system of military engineering construction is huge, project management methods and thinking models are deeply entrenched. Under the premise of pursuing speed and efficiency, it is difficult to use the advantages of new technologies, and it is difficult to adapt to changes in models. The military's recognition of BIM is low and it is difficult to promote. Lack of industry experience risk: at present, our military has fewer precedents for applying BIM to engineering project construction management. Engineering construction can only learn from local engineering projects. Insufficient experience makes it difficult to promote and apply. Project management goals difficult to achieve risk: military engineering construction project schedule tightness, heavy tasks, high cost requirements, many influencing factors of BIM application effect, application effect is difficult to guarantee, project management objectives are difficult to achieve. Legal risk: BIM related legal liability boundaries are unclear, disputes arise and cannot be resolved.

\subsection{Technical risks}

In the technical risk, the technical situation, technical data and related documents need to be considered.

BIM model accuracy risk: during the implementation of the project, the accuracy of the BIM model data is difficult to control, too high or too low will not match the actual construction situation, low-precision models have limited effect, and high-precision causes waste of manpower and material resources. Software maturity risk: there are many BIM related softwares, including BIM solution software Affinity, BIM structural analysis software Robot, BIM visualization software Artlantis, BIM model comprehensive collision inspection software Autodesk Navisworks, BIM cost management software Innovaya, Glodon, BIM operation software ArchiBUS. However, some software technologies are immature and cannot fully meet actual needs. Data interaction risk: a project requires different software to work together. Although there are many types of BIM-related software, the data interaction between different software is poor, and there are different degrees of data interaction. Technology applicability risk: BIM originated from abroad and does not match the development stage of China's construction industry. When applied in the military, the applicability is not high. Technical difficulty risk: BIM has higher technical requirements than there are obvious differences in the concepts of traditional methods, and it is difficult to apply them in practice. Model update frequency risk: The integration of BIM drawing software makes its internal calculations slower than traditional 2D design software. BIM models cannot be updated in time with the actual situation of the project, exerting its own value. It will only increase the construction cost, and the construction progress will be delayed. Based on the above analysis, the BIM application risk evaluation index system for military engineering project management is obtained, as shown in Table I.

\section{Risk analysis and assessment}

Regarding risk evaluation, methods such as fuzzy comprehensive evaluation method, analytic hierarchy process, and Delphi method are used frequently and rely on experts to a greater degree. When the index system is too large, the workload is large and it is easy to cause errors in expert judgment. Neural network analysis is generally composed of neurons, including an input layer, an output layer, and a hidden layer. The connections between neurons give relevant weights. The training learning algorithm continuously adjusts the connection 
weights in the iterative process to minimize the prediction error and give the prediction accuracy, avoiding the problem of weak objectivity caused by the scoring of experts ${ }^{[15-17]}$. The neural network algorithm, using the built-in functions in the software, can calculate the importance of the lowest level indicators to the top level, and directly get the risk evaluation of the target level, eliminating a lot of intermediate calculations, and generating charts, and the analysis results are more intuitive and clear. Therefore, this article uses the abovementioned index system to design a questionnaire about the risk of military engineering project management BIM application, collects and summarizes the data, and uses the neural network analysis module in the SPSS software to realize data processing and prediction.

The content of the questionnaire includes the type of person who filled out the questionnaire and the number of years of BIM employment, so as to ensure the professionalism of the person who filled out the questionnaire and the referenceability of the data. A total of 200 people participated in the questionnaire. Most of the personnel types are closely related to engineering construction and BIM, and most of them have been employed for more than 3 to 5 years, which meets the professionalism of personnel and the data can be referenced.

Table I. BIM application risk assessment index system for military engineering project management

\begin{tabular}{|c|c|c|}
\hline $\begin{array}{l}\text { First-level } \\
\text { indicators }\end{array}$ & $\begin{array}{l}\text { Second-level } \\
\text { indicators }\end{array}$ & $\begin{array}{l}\text { Third-level } \\
\text { indicators }\end{array}$ \\
\hline \multirow{16}{*}{$\begin{array}{c}\text { Military } \\
\text { engineering } \\
\text { project } \\
\text { management } \\
\text { and } \\
\text { management } \\
\text { of BIM } \\
\text { application } \\
\text { risk }\end{array}$} & \multirow{4}{*}{$\begin{array}{l}\text { Organizational } \\
\text { risk }\end{array}$} & $\begin{array}{l}\text { Business process } \\
\text { reorganization risk }\end{array}$ \\
\hline & & $\begin{array}{l}\text { Participating party } \\
\text { cooperation risk }\end{array}$ \\
\hline & & BIM implementer risk \\
\hline & & Operator initiative risk \\
\hline & \multirow{5}{*}{$\begin{array}{c}\text { Economic and } \\
\text { management } \\
\text { risk }\end{array}$} & $\begin{array}{c}\text { Unclear BIM requirements } \\
\text { risk }\end{array}$ \\
\hline & & Resource risk \\
\hline & & Security management risk \\
\hline & & $\begin{array}{l}\text { Feasibility of plan } \\
\text { implementation risk }\end{array}$ \\
\hline & & Contract risk \\
\hline & \multirow{6}{*}{$\begin{array}{c}\text { Engineering } \\
\text { environment } \\
\text { risk }\end{array}$} & Lack of standard risk \\
\hline & & Insufficient acceptance risk \\
\hline & & Recognition risk \\
\hline & & $\begin{array}{c}\text { Lack of industry experience } \\
\text { risk }\end{array}$ \\
\hline & & $\begin{array}{l}\text { Project management goals } \\
\text { difficult to achieve risk }\end{array}$ \\
\hline & & legal risk \\
\hline & Technology risk & BIM model accuracy risk \\
\hline
\end{tabular}

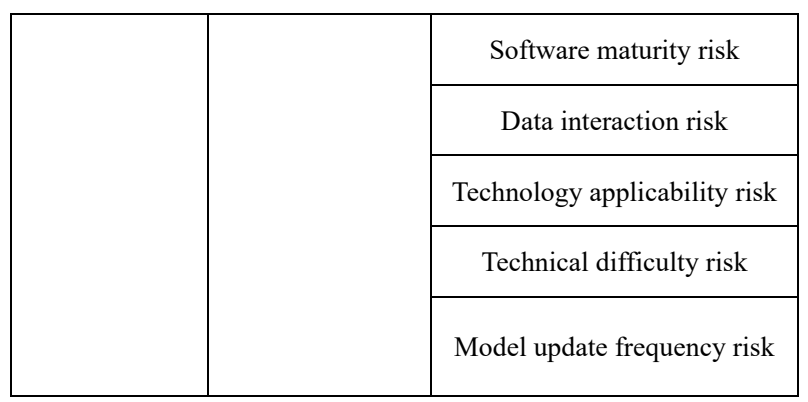

A total of 200 questionnaires were distributed this time including 50 from a military engineering construction unit, 50 from a military engineering agency, 30 from China Metallurgical Construction Investment Co., Ltd. (Inner Mongolia), 50 from a BIM consulting company in Baotou, Ningxia 20 copies of Architectural Design and Research Institute, a total of 200 copies were recovered, and the effective recovery rate was $100 \%$. Before data analysis, set $70 \%$ of the data as the training sample, $10 \%$ as the persistence sample, and $20 \%$ as the test sample to test the accuracy of the prediction. Set 21 risk indicators as factors, which belong to the input layer. In the questionnaire, the military engineering project application BIM risk degree is set as the only dependent variable, which belongs to the output layer.

Input the effective recovery questionnaire data into the software, and use the neural network module to train and learn. Through the output results, we can get that the analysis uses 200 points of valid data, including 142 training samples, 15 testing, and 43 holdings. In Table 3, there is no description of "exceeding the maximum number of time courses", and it can be determined that there is no over-learning. The percentage error prediction of training data is $4.9 \%$, the percentage error prediction data is $20.9 \%$, and the percentage error prediction of test data is $6.7 \%$. The output result is very good, which fully shows that the prediction rate for the sample is strong, and when the sample size is large enough. The percentage error rate will be lower and the accuracy will be higher, as shown in Table II and Table III.

Table II. Case processing summary

\begin{tabular}{|c|c|c|c|}
\hline \multicolumn{2}{|c|}{} & $N$ & percentage \\
\hline \multirow{3}{*}{ sample } & train & 142 & $71.0 \%$ \\
\cline { 2 - 4 } & test & 15 & $7.5 \%$ \\
\cline { 2 - 4 } & maintain & 43 & 21.5 \\
\hline \multicolumn{2}{|c|}{ effective } & 200 & $100.0 \%$ \\
\hline \multicolumn{2}{|c|}{ excluded } & 0 & \\
\hline \multicolumn{2}{|c|}{ total } & 200 & \\
\hline
\end{tabular}

Table III. The model summary

\begin{tabular}{|l|c|c|}
\hline \multirow{3}{*}{ train } & Cross entropy error & 20.274 \\
\cline { 2 - 3 } & Percentage error prediction & $4.9 \%$ \\
\hline
\end{tabular}




\begin{tabular}{|c|c|c|}
\hline \multirow{2}{*}{ test } & Discontinued rules & $\begin{array}{c}\text { Steps with } \\
\text { unreduced errors }\end{array}$ \\
\cline { 2 - 3 } & training period & $0: 00: 00.09$ \\
\cline { 2 - 3 } & Cross entropy error & 1.857 \\
\hline maintain & Percentage error prediction & $6.7 \%$ \\
\hline
\end{tabular}

According to the results of the importance of the independent variables, the importance percentage of each factor to the BIM application risk of the dependent variable is greater than $50 \%$ of the standardization importance of more than 16 indicators, which also confirms that the indicator system is basically qualified. Resource risk, safety management risk, business process reorganization risk, operator initiative risk, and plan implementation feasibility risk all exceed $90 \%$, indicating that these five factors have an important impact on military engineering BIM application risks. These risks should be focused on during the project management process. The standardization importance of recognition risk, legal risk, and lack of standard risk are all less than $50 \%$, which can be appropriately paid attention to, as shown in Figure 1.

According to the test probability data, it is believed that $80.0 \%$ of the military engineering project management BIM application risk is high risk, and the rest is medium risk.The correct percentage of predictions for medium risk, higher risk and highest risk is $93.3 \%$, which is considered that the risk level of the BIM application risk in the military engineering project management of the dependent variable is relatively high. The possibility and the consequences of the risk should be fully analyzed and judged during the application, as shown in Table IV.

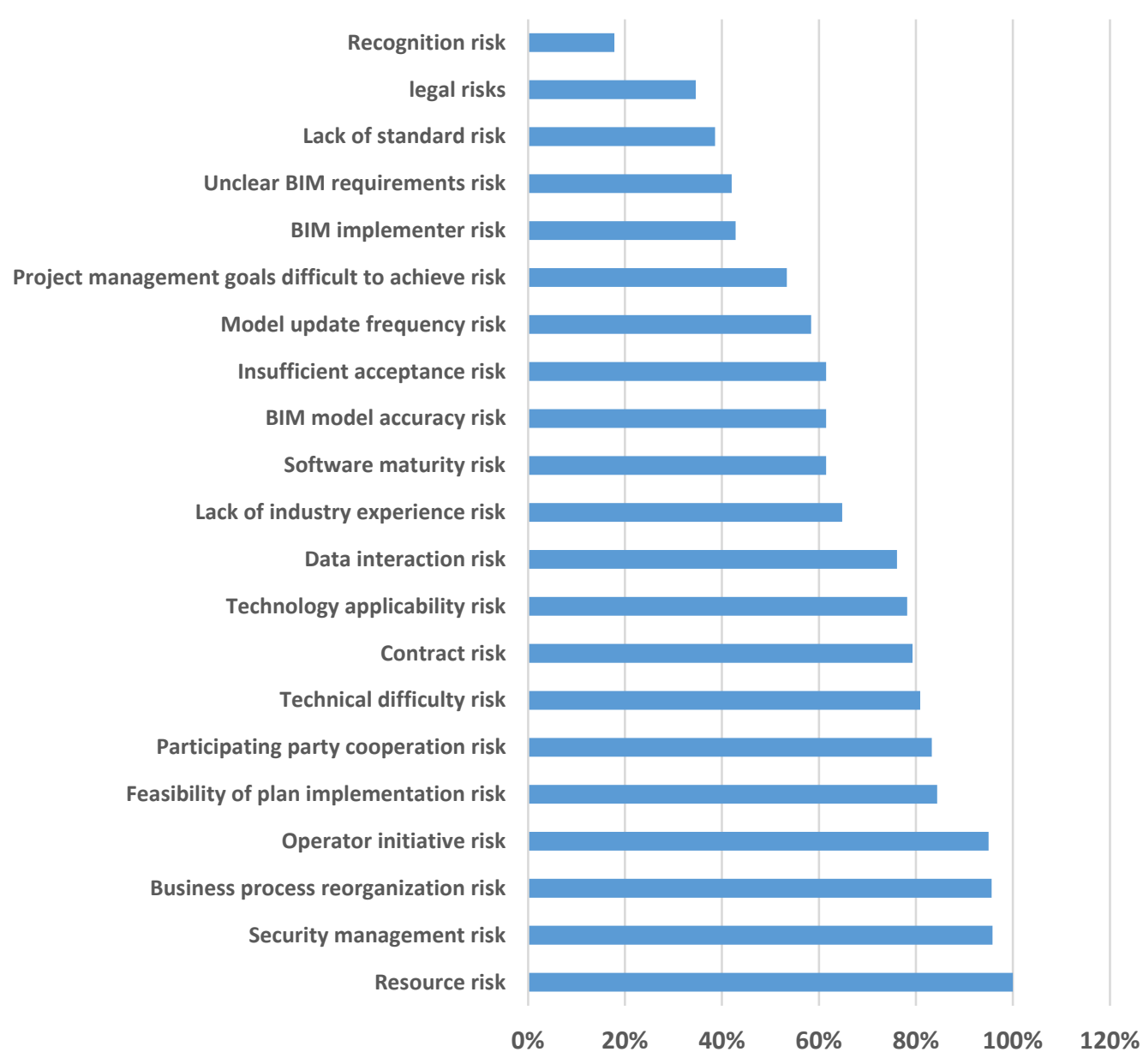

Figure 1. The importance of standardization of independent variables

\section{Risk response strategy}

Based on the above data analysis, we propose coping strategies to reduce, control, and guard against the important factors of military engineering project management BIM application risks.
Pay more attention to the application of BIM technology, project planning and design stage, increase BIM related investment, including the development of auxiliary software, increase the interactivity between data, and improve the implementability of BIM applications in engineering projects. Strengthen the professional training of relevant personnel in the military, improve professional skills, and enhance the concept of BIM. In the face of 
complex conditions, the quality of the model is still completed to ensure the accuracy of the model, so as to meet the construction requirements, shorten the BIM modeling time in the application, adapt to the characteristics of military engineering projects, and update the model to keep up with the progress.

Table IV. The model summary

\begin{tabular}{|c|c|c|c|c|c|}
\hline \multirow[b]{2}{*}{ sample } & \multirow[b]{2}{*}{ Observed } & \multicolumn{4}{|c|}{ Predicted } \\
\hline & & $\begin{array}{c}\text { Medium } \\
\text { risk }\end{array}$ & $\begin{array}{c}\text { Higher } \\
\text { risk }\end{array}$ & $\begin{array}{c}\text { Highest } \\
\text { risk }\end{array}$ & $\begin{array}{c}\text { Correct } \\
\text { percentage }\end{array}$ \\
\hline \multirow{4}{*}{ train } & $\begin{array}{c}\text { Medium } \\
\text { risk }\end{array}$ & 23 & 1 & 0 & $95.8 \%$ \\
\hline & $\begin{array}{c}\text { Higher } \\
\text { risk }\end{array}$ & 0 & 59 & 2 & $96.7 \%$ \\
\hline & $\begin{array}{c}\text { Highest } \\
\text { risk }\end{array}$ & 4 & 0 & 53 & $93.0 \%$ \\
\hline & $\begin{array}{l}\text { Percent } \\
\text { of total }\end{array}$ & $19.0 \%$ & $42.3 \%$ & $38.7 \%$ & $95.1 \%$ \\
\hline \multirow{4}{*}{ test } & $\begin{array}{c}\text { Medium } \\
\text { risk }\end{array}$ & 2 & 0 & 0 & $100.0 \%$ \\
\hline & $\begin{array}{l}\text { Higher } \\
\text { risk }\end{array}$ & 0 & 8 & 0 & $100.0 \%$ \\
\hline & $\begin{array}{l}\text { Highest } \\
\text { risk }\end{array}$ & 1 & 0 & 4 & $80.0 \%$ \\
\hline & $\begin{array}{l}\text { Percent } \\
\text { of total }\end{array}$ & $20.0 \%$ & $53.3 \%$ & $26.7 \%$ & $93.3 \%$ \\
\hline \multirow{4}{*}{ maintain } & $\begin{array}{c}\text { Medium } \\
\text { risk }\end{array}$ & 5 & 1 & 2 & $62.5 \%$ \\
\hline & $\begin{array}{c}\text { Higher } \\
\text { risk }\end{array}$ & 0 & 16 & 2 & $88.9 \%$ \\
\hline & $\begin{array}{l}\text { Highest } \\
\text { risk }\end{array}$ & 4 & 0 & 13 & $76.5 \%$ \\
\hline & $\begin{array}{l}\text { Percent } \\
\text { of total }\end{array}$ & $20.9 \%$ & $39.5 \%$ & $39.5 \%$ & $79.1 \%$ \\
\hline
\end{tabular}

To speed up the formulation of related policies and regulations and to make up for the current military lack of related content. To accelerate the popularization and application of BIM in military project. Make decision makers have laws to follow and documents to check. In practical application, the responsibilities, rights and interests of the participants are determined by standard contracts, the whole life cycle of the project will be more clearer, the recognition of BIM within the military will also increase.

The military and local sides can enhance relevant exchanges, especially the senior military personnel can learn more about relevant knowledge, learn from local experience, strengthen the importance of BIM, and drive the initiative of lower-level operators. To make BIM standards more complete, Organizational processes more comprehensive, think more carefully about risk. It is beneficial to realize the effective use of BIM according to the actual situation in the military.

The BIM application of engineering projects in the military is still blank. Therefore, in the initial contact, can refer to large local enterprises and conduct pilots in the military to test the actual application effects.

\section{Conclusion}

By analyzing the disadvantages of military engineering construction and the advantages of BIM application in military engineering project management, this paper determines the urgency and necessity of risk management of BIM application in military engineering projects. By referring to a large number of literature and combining with years of military engineering practice and expert interviews, the index system of 21 indicators covering four aspects, including organization, economic management, engineering environment and technology. The risk framework of BIM application in military engineering project management is constructed.

On this basis, through the analysis of the advantages and disadvantages of various methods, the final use of SPSS software based on neural network comprehensive evaluation method, in order to achieve more objective prediction results. Based on this, the data collected from the questionnaire are processed and the predictive analysis is carried out. Resource risk, security risk management, risk, operations staff initiative risk, business process reengineering plan feasibility for influence BIM applications risk degree is bigger, think the military project management application plus high overall risk, and puts forward four strategies, the army has guiding significance for engineering project management BIM application in the future.

\section{References}

1. Ren,Y.,Huang,W,Wu,J. (2011) Research on Integrated Risk Management of Military Engineering Projects. Military Economic Research, 32: 61-64.

2. Fan Zheng(Chinese Master's Theses Full-text Database), 2010. Research on Problems and Its Settlement in Construction Management of Military Barracks

Engineering.https://oversea.cnki.net/kns/detail/detail. aspx?FileName $=1011279595$. nh $\&$ DbName $=$ CMFD2 012

3. Osan Diane R K,Hule Marty A,Nguyen Quy,Gaitan Daniel A(Health facilities management), 2012.The BIM revolution. Building information modeling expands, benefits to hospital design and operations. https://oversea.cnki.net/kns/detail/detail.aspx?FileNa $\mathrm{me}=\mathrm{SJPD} 120727372551 \& \mathrm{DbName}=\mathrm{GARJ} 2012$.

4. Jingming Li,Kereshmeh Afsari,Nianping Li,Jinqing Peng,Zhibin Wu,Haijiao Cui(Journal of Cleaner Production),2020.A review for presenting building information modeling education and research in China. 
https://oversea.cnki.net/kns/detail/detail.aspx?FileNa me=SJESD36640D71267614827F5B5314B2F9BF3 $\&$ DbName $=$ GARJ 2020

5. He,G.(2012) China Construction Industry BIM Survey Report 2011"Analysis. Journal of Information Technology in Civil Engineering and Architecture, $4: 15-21$.

6. He,Q.Qian,L.Duan,Y.(2012) Current Situation and Barriers of BIM Implementation. Journal of Engineering Management, 26: 12-16.

7. Ministry of Construction Information Work Leading Group(Intelligent Building),2004.The Tenth FiveYear Plan for the Informatization of Construction. Business.https://oversea.cnki.net/kns/detail/detail.asp $\mathrm{x}$ ?FileName $=$ ZNJZ200403001\&DbName $=$ CJFQ200 4

8. Pan,J.Zhao,J.Zhao,Y.(2012) Research on Barriers of BIM Application in China's Building Industry . Journal of Engineering Management, 26:6-11.

9. Zhou,S.Pang,B.Pan,Y.Zhang,Q.Lu,Y.(2020)

Analysis on Research Hotspots and Trends Based on BIM Papers. Journal of Information Technology in Civil Engineering and Architecture, 12:8-15.

10. Chi,J.(2017) Problems and Strategies in the Construction and Management of Military Barracks. 'Housing and Real Estate, 15:212.

11. Li,Yawei. (Chinese Master's Theses Full-text Database) 2016. Research on Risk Assessment of BIM Application in Construction Project. https://oversea.cnki.net/kns/detail/detail.aspx?FileNa $m e=1016908434 . n h \& D b N a m e=C M F D 2017$

12. Zhi,Pengyu. (Chinese Master's Theses Full-text Database)2019. Research on the Application of BIM Technology in Military Agent Construction Engineering. https://tra.oversea.cnki.net/KCMS/detail/detail.aspx? dbname $=$ CMFD202002 $\&$ filename $=1020025848 . \mathrm{nh}$

13. Cui,Zongju. (Chinese Master's Theses Full-text Database)2017. Research on Engineering Project Management Based on BIM. https://kns.cnki.net/KCMS/detail/detail.aspx?dbnam $\mathrm{e}=\mathrm{CMFD} 201702 \&$ filename $=1017133770 . \mathrm{nh}$

14. Luo,Hao. (Chinese Master's Theses Full-text Database)2017. A Research for Project Management Evaluation for Investors Based on BIMSystem. https://tra.oversea.cnki.net/KCMS/detail/detail.aspx? dbname $=$ CMFD201902\&filename $=1019877389 . \mathrm{nh}$

15. Mao,J.Zhao,H.Yao,J.(2011) Application and prospect of Artificial Neural Network. Electronic Design Engineering, 19:62-65.

16. Wang,A.(1995) A Study on the Application of Neural Networks in Fuzzy Comprehensive Evaluationang. Henan Science, 2:132-137.

17. Yan,Jie. (Chinese Master's Theses Full-text Database) 2017.Research on Supply Chain Risk Identification and Evaluation of $\mathrm{Z}$ Company Based on Fuzzy Comprehensive Evaluation Method and Neural Network Comprehensive Evaluation Method.Chinese
Master's Theses Full-text Database. https:// oversea. cnki.net/kns/detail/detail.aspx?FileName $=10171239$ 48.nh\&DbName $=$ CMFD2018 